\title{
ANALISIS KADAR NATRIUM BENZOAT DALAM KECAP MANIS PRODUKSI HOME INDUSTRI YANG BEREDAR DI KOTA MAKASSAR DENGAN METODE SPEKTROFOTOMETRI UV-Vis
}

\author{
Hj. Nurisyah*) \\ *) Jurusan Farmasi Poltekkes Kemenkes Makassar
}

\begin{abstract}
ABSTRAK
Telah dilakukan penelitian dengan tujuan untuk menentukan kadar pengawet natrium benzoat dalam kecap manis produksi home industri yang beredar di Kota Makassar dengan metode spektrofotometri UV-Vis, dan menentukan kesesuaian kadar natrium benzoat tersebut dengan standar yang ditetapkan. Sampel penelitian ini berupa kecap manis kemasan isi ulang yang diambil dari Pasar Pa'baeng-baeng dan Pasar Terong Kota Makassar. Untuk menentukan kandungan pengawet natrium benzoat, maka terlebih dahulu dilakukan ekstraksi senyawa benzoat dalam suasana asam dengan kloroform sehingga terekstraksi sebagai asam benzoat. Ekstrak kloroform dikeringkan lalu dilarutkan dengan etanol. Kemudian diukur serapannya dengan spektrofotometer UV-Vis pada panjang gelombang maksimum $270 \mathrm{~nm}$. Hasil analisis menunjukkan bahwa kadar pengawet natrium benzoat yang dihitung sebagai asam benzoat pada masing-masing sampel adalah sampel A sebesar $407,1124 \mathrm{mg} / \mathrm{kg}$; sampel B sebesar $499,9675 \mathrm{mg} / \mathrm{kg}$; sampel C sebesar $347,7474 \mathrm{mg} / \mathrm{kg}$; dan sampel D sebesar 328,7509 mg/kg. Berdasarkan hasil tersebut maka dapat disimpulkan bahwa kandungan pengawet natrium benzoat dalam ke 4 sampel kecap manis yang dianalisis memenuhi persyaratan yang ditetapkan dalam SNI 01-2543-1999 dan Peraturan Kepala BPOM RI No. 36 tahun 2013 yaitu tidak lebih dari $600 \mathrm{mg} / \mathrm{kg}$.
\end{abstract}

\section{Kata kunci : Kecap manis, pengawet, natrium benzoat, spektrofotometri UV-Vis}

\section{PENDAHULUAN.}

Teknologi pengolahan pangan di Indonesia sekarang berkembang cukup pesat, diiringi dengan penggunaan bahan tambahan pangan yang juga makin meningkat. Bahan tambahan makanan adalah bahan yang ditambahkan dengan sengaja ke dalam makanan dalam jumlah kecil, dengan tujuan untuk memperbaiki penampakan, cita rasa, tekstur, flavor dan memperpanjang daya simpan. Berkembangnya produk pangan awet saat ini, hanya mungkin terjadi karena semakin tingginya kebutuhan masyarakat terhadap berbagai jenis makanan yang praktis dan awet. Kesalahan teknologi dan penggunaan bahan tambahan yang diterapkan, baik sengaja maupun tidak disengaja dapat menyebabkan gangguan pada kesehatan dan keamanan konsumen (Anggrahini, 2012).

$$
\text { Kecap merupakan salah satu }
$$

produk yang banyak dikonsumsi oleh masyarakat baik ditambahkan dengan makanan maupun tidak. Kecap dijadikan oleh masyarakat Indonesia sebagai menu harian, sehingga dari tahun ke tahun kebutuhannya semakin meningkat. Asam benzoat sering digunakan sebagai bahan pengawet pada produk kecap agar waktu simpan produk lebih lama (Widjajarta, 2010.

Asam benzoat disebut juga senyawa antimikroba karena tujuan penggunaan zat pengawet ini dalam produk kecap adalah untuk mencegah pertumbuhan khamir dan bakteri terutama untuk makanan yang telah dibuka dari kemasannya. Jumlah maksimum benzoat yang boleh digunakan pada kecap manis adalah $600 \mathrm{mg}$ per $\mathrm{kg}$ sesuai dengan spesifikasi persyaratan mutu kecap manis (SNI 01-2543-1999). Jumlah maksimum yang sama yaitu $600 \mathrm{mg} / \mathrm{kg}$ yang dihitung sebagai asam benzoat, juga disebutkan dalam Peraturan Kepala BPOM RI No. 36 tahun 2013 tentang batas maksimum penggunaan bahan tambahan pengawet.(BPOM, 2013)

$$
\text { Pembatasan penggunaan asam }
$$
benzoat bertujuan agar tidak terjadi keracunan. Konsumsi asam benzoat yang berlebihan dalam suatu bahan makanan tidak dianjurkan karena jumlah zat pengawet yang masuk ke dalam tubuh akan bertambah 
dengan semakin banyak dan seringnya mengkonsumsi. Hal tersebut akan diperparah jika dibarengi dengan konsumsi makanan awetan lain yang mengandung asam benzoat (Lutfi, 2009).

Asam benzoat lebih banyak digunakan dalam bentuk garamnya karena kelarutannya lebih baik daripada bentuk asamnya. Bentuk garam dari asam benzoat yang banyak digunakan adalah natrium benzoat. Benzoat dan turunannya dapat menghancurkan sel-sel mikroba terutama kapang. Natrium benzoat bekerja efektif pada $\mathrm{pH}$ 2,5-4 sehingga banyak digunakan pada makanan atau minuman yang bersifat asam (Winarno, 1990).

Kebanyakan kecap manis produksi home industri yang di gunakan oleh pedagang makanan di Kota Makassar misalanya penjual coto dan sari laut yang di beli dalam bentuk kemasan ulang (jerigen) tidak mencantumkan kandungan (label) terkhusus bahan pengawet pada kemasannya secara jelas, sehingga belum diketahui apakah kadar senyawa benzoat yang digunakan melebihi ambang batas yang ditentukan oleh Peraturan Kepala BPOM RI No. 36 tahun 2013 maupun oleh spesifikasi persyaratan mutu kecap manis (SNI 012543-1999) atau tidak. Dalam UndangUndang Nomor 18 tahun 2012 tentang pangan disebutkan bahwa setiap orang yang melakukan produksi pangan untuk diedarkan dilarang menggunakan bahan tambahan pangan yang melampau ambang batas maksimal yang ditetapkan.

Berdasarkan latar belakang di atas, maka dirumuskan permasalahan penelitian ini yaitu berapakah kadar pengawet natrium benzoat dalam kecap manis produksi Home Industri yang beredar di Kota Makassar ?, dan apakah kadar pengawet natrium benzoat tersebut memenuhi standar yang ditentukan pada Spesifikasi persyaratan mutu kecap manis (SNI 01-2543-1999) dan Peraturan Kepala BPOM RI No. 36 tahun 2013 yaitu $600 \mathrm{mg} / \mathrm{kg}$ asam benzoat?.

Tujuan penelitian ini adalah untuk menentukan kadar pengawet natrium benzoat dalam kecap manis produksi Home Industri yang beredar di Kota Makassar, dan menentukan kesesuaian kadar natrium benzoat tersebut dengan standar yang ditetapkan dalam spesifikasi persyaratan mutu kecap manis (SNI 01-2543-1999) dan
Peraturan Kepala BPOM RI No. 36 tahun 2013 yaitu $600 \mathrm{mg} / \mathrm{kg}$.

Sedangkan manfaat yang diharapkan dari penelitian ini yakni dapat memberikan penjelasan secara ilmiah atas asumsi masyarakat terhadap bahan pengawet dalam kecap manis juga memberikan informasi apakah penggunaan natrium benzoat pada kecap manis produ home industri di Kota Makassar sesuai dengan standar Nasional Indonesia serta juga dapat dijadikan bahan referensi untuk penelitian berikutnya yang terkait dengan penelitian ini.

\section{METODE DAN BAHAN Jenis Penelitian}

Penelitian ini adalah penelitian observasi laboratorium yang dilakukan untuk menentukan kadar pengawet natrium benzoat dalam kecap manis produksi Home Industri yang beredar di Kota Makassar, dan menentukan kesesuaian kadar natrium benzoat tersebut dengan standar yang ditetapkan dalam spesifikasi persyaratan mutu kecap manis (SNI 01-2543-1999) dan $\mathrm{P}$ eraturan Kepala BPOM RI No. 36 tahun 2013 yaitu $600 \mathrm{mg} / \mathrm{kg}$.

\section{Waktu dan Tempat Penelitian}

Penelitian ini telah dilakukan pada bulan Pebruari 2018, di Laboratorium Kimia Jurusan Farmasi Politeknik Kesehatan Makassar.

\section{Alat dan Bahan Yang Digunakan}

Alat yang digunakan dalam penelitian ini adalah alat-alat gelas, neraca analitik, dan Spektrofotometer UV-Vis. Bahan yang digunakan dalam penelitian ini adalah sampel kecap manis, besi (III) klorida p.a, aquadest, natrium klorida p.a, natrium hidroksida p.a, asam klorida p.a, kloroforom, etanol, amoniak, indicator universal, dan kertas saring.

\section{Pengambilan Sampel}

Sampel penelitian ini adalah kecap manis produksi Home Industri yang beredar di Kota Makassar, sampel berupa kecap manis kemasan isi ulang diambil dari pasar Pa'ban-baeng dan pasar Terong kota Makassar tempat membelinya lansung penjual coto dan sari laut yang ada di Kota Makassar. 


\section{Pengumpulan Data}

1. Pembuatan larutan pereaksi

a. Larutan $\mathrm{HCl} 3 \mathrm{M}$

Diukur $125 \mathrm{~mL} \mathrm{HCl}$ pekat, dimasukkan ke dalam labu ukur $500 \mathrm{~mL}$ yang telah berisi air suling 250 mL. Dikocok, kemudian dicukupkan volumenya dengan air suling hingga tanda.

b. Larutan $\mathrm{NaOH} 10 \%$

Ditimbang $25 \mathrm{~g} \mathrm{NaOH}$ dalam gelas piala $100 \mathrm{~mL}$, ditambah $50 \mathrm{~mL}$ air suling. Diaduk hingga $\mathrm{NaOH}$ larut, kemudian dimasukkan ke dalam labu ukr $250 \mathrm{~mL}$. Dicukupkan volumenya dengan air suling hingga tanda.

c. Larutan $\mathrm{NaCl}$ jenuh

Diukur air suling sebanyak $100 \mathrm{~mL}$, dimasukkan ke dalam gelas piala 250 mL. Ditambahkan $\mathrm{NaCl}$ sedikit demi sedikit sambil diaduk, penambahan $\mathrm{NaCl}$ terus dilakukan sampai penambahan $\mathrm{NaCl}$ tidak dapat larut lagi. Larutan dienap tuangkan, kemudian larutan dipisahkan dari kristal yang tidak larut.

2. Pembuatan larutan sampel (Siaka, 2009)

Masing-masing sampel ditimbang saksama sebanyak $20 \mathrm{~g}$ dan ditambahkan $1 \mathrm{~g} \mathrm{NaCl}$, kemudian dimasukkan ke dalam labu takar $50 \mathrm{ml}$. Selanjutnya ke dalam labu takar tersebut ditambahkan $20 \mathrm{ml}$ larutan $\mathrm{NaCl}$ jenuh dan $\mathrm{NaOH} 10 \%$ hingga diperoleh larutan yang bersifat alkalis (mengubah lakmus merah jadi biru). Larutan tersebut diencerkan dengan larutan $\mathrm{NaCl}$ jenuh sampai tanda batas dan dibiarkan selama 2 jam. Larutan tersebut dikocok setiap 30 menit dan selanjutnya disaring dengan kertas saring. Filtrat yang diperoleh dimasukkan ke dalam corong pisah, kemudian ditambah $\mathrm{HCl} 3 \mathrm{M}$ hingga larutan bersifat asam (mengubah lakmus biru jadi merah). Kemudian diekstraksi dengan pelarut kloroform dengan volume berturut-turut $25 ; 15$; dan 10 $\mathrm{mL}$. Lapisan kloroform ditampung dan diuapkan dengan rotary evaporator pada suhu $50{ }^{0} \mathrm{C}$ hingga volume $\pm 5 \mathrm{ml}$, diuapkan di atas waterbath dalam lemari asam hingga kering. Ekstrak kering dilarutkan dengan etanol sampai 25,0 $\mathrm{ml}$.

3. Analisis kadar

a. Pembuatan larutan baku induk asam benzoat

Ditimbang saksama $10 \mathrm{mg}$ asam benzoat, dimasukkan ke dalam labu ukur $20 \mathrm{~mL}$. Ditambahkan etanol beberapa $\mathrm{mL}$, dikocok hingga larut. Kemudian dicukupkan volumenya dengan etanol hingga tanda (500 ppm). kemudian diukur 10,0 ml dan dimasukkan kedalam labu ukur 100 $\mathrm{ml}$, dan dicukupkan volumenya dengan etanol hingga tanda (50 ppm).

b. Pembuatan larutan baku kerja

Larutan standar dibuat dengan mengukur saksama 0,$5 ; 1,0 ; 1,5$; 2,0; dan 2,5 mL larutan induk asam benzoat 50 ppm ke dalam labu ukur $10 \mathrm{~mL}$ kemudian masing-masing diencerkan dengan etanol sampai tanda batas. Konsentrasi larutan standar yang diperoleh berturutturut ialah 2,$5 ; 5,0 ; 7,5 ; 10,0$ dan $12,5 \mathrm{ppm}$.

4. Penentuan panjang gelombang maksimum

Larutan baku kerja 10,0 ppm diukur serapannya dengan spektrofotometer UV-Vis pada panjang gelombang 200-400 nm menggunakan blanko pelarut etanol.

5. Pembuatan kurva standar

Larutan baku kerja asam benzoat 2,$5 ; 5,0 ; 7,5 ; 10,0$ dan 12,5 ppm, masing-masing diukur serapannya pada panjang gelombang maksimum. Selanjutnya dibuat kurva standar yang menghubungkan absorbansi dengan konsentrasi dari masing-masing larutan standar.

6. Penentuan kadar asam benzoat pada kecap

Larutan hasil ekstraksi diukur sebanyak 1,0 mL, dimasukkan kedalam labu ukur $10 \mathrm{~mL}$. diencerkan dengan etanol hingga tanda. Kemudian dikur 1,0 $\mathrm{mL}$ larutan tersebut, dimasukkan kembali ke dalam labu ukur $10 \mathrm{ml}$ dan dicukupkan volumenya hingga tanda dengan etanol. Kemudian larutan sampel dibaca absorbansinya dengan 
menggunakan spektrofotometer UV-Vis pada panjang gelombang maksimum, kemudian konsentrasi asam benzoat dalam sampel ditentukan berdasarkan kurva standar.

\section{Analisis Data}

Data hasil pengukuran kurva baku dibuat persamaan garis regresi, $\mathrm{y}=\mathrm{bx}+\mathrm{a}$. Kemudian kadar sampel dihitung berdasarkan persamaan garis regresi tersebut.

\section{HASIL DAN PEMBAHASAN \\ Hasil Penelitian}

Berdasarkan hasil penelitian terhadap $\mathrm{k}$ adar pengawet natrium benzoat dalam sampel kecap manis produksi Home Industri yang beredar di Kota Makassar dengan spektrofotometri UV-Vis, maka diperoleh hasil penelitian sebagai berikut:

Tabel 2. Hasil analisis kadar pengawet natrium benzoat yang dihitung sebagai asam benzoat dalam sampel kecap manis kecap manis produksi Home Industri yang beredar di Kota Makassar

\begin{tabular}{cc}
\hline Sampel & $\begin{array}{c}\text { Kadar rata-rata asam } \\
\text { benzoat } \\
(\mathrm{mg} / \mathrm{kg})\end{array}$ \\
\hline A & 480,5258 \\
B & 590,1256 \\
C & 410,4560 \\
D & 396,6120 \\
\hline
\end{tabular}

\section{Pembahasan}

Sampel yang dianalisis dalam penelitian ini adalah kecap manis kemasan produk home industri sebanyak 4 produk yang berbeda yang diambil dari pasar tradisional Pa'baeng-baeng dan pasar terong Kota Makassar. Pada produk masingmasing sampel kecap yang dianalisis menunjukkan bahwa sampel tersebut mengandung bahan pengawet natrium benzoat. Oleh karena sampel telah dinyatakan mengandung pengawet natrium benzoat, maka tidak lagi dilakukan analisis kualitatif. Sampel langsung dianalisis secara kuantitatif untuk mengetahui seberapa besar kadar pengawet natrium benzoat yang terdapat dalam masing-masing sampel tersebut. Karena pada kemasan tidak dicantumkan jumlah pengawet natrium benzoat yang digunakan.

Analisis dimulai dengan menimbang sampel kecap sebanyak 20 gram ditambahkan larutan garam $\mathrm{NaCl}$ jenuh untuk memecahkan emulsi kecap manis, karena emulsi dapat dipecahkan dengan menambahkan elektrolit. Tujuan lain dari penambahan larutan $\mathrm{NaCl}$ jenuh adalah untuk menambah tingkat ionisasi dari air menjadi lebih polar sehingga tingkat tidak bercampurnya air dengan kloroform akan bertambah yang bermanfaat dalam pemisahan fase. Penambahan larutan $\mathrm{NaOH}$ $10 \%$ bertujuan untuk mengalkaliskan larutan sampel, sehingga seluruh benzoat terdapat sebagai garamnya yang larut dalam air. Air

Larutan sampel yang telah disaring, kemudian diasam kan dengan $\mathrm{HCl} 3 \mathrm{M}$. Tujuan pengasaman untuk membuat senyawa benzoat kembali menjadi asam benzoat yang tidak larut dalam air tapi larut dalam pelarut organik (kloroform). Dengan demikian hasil ekstraksi cair-cair menggunakan corong pisah, pengawet benzoat berada pada fase organik/kloroform tersebut.

Kadar pengawet natrium benzoat dapat diketahui dengan menggunakan spektrofotometer UV-Vis. Penentuan panjang gelombang maksimum yang digunakan dalam pengukuran absorbansi larutan standar asam benzoat maupun larutan sampel ditentukan dengan mengukur nilai absorbansi maksimum larutan standar asam benzoat $100 \mathrm{ppm}$. Untuk memperoleh panjang gelombang maksimum pengukuran absorbansi dilakukan pada rentang panjang gelombang 240 - $400 \mathrm{~nm}$. Hasil pengamatan untuk absorbansi maksimum adalah pada panjang gelombang $270 \mathrm{~nm}$ (hasil selengkapnya dapat dilihat pada Lampiran 1)

Kemudian dilakukan penentuan nilai absorbansi pada lima deret larutan standar, yang selanjutnya digunakan sebagai kurva standar. Dari kurva standar antara absorbansi terhadap konsentrasi diperoleh persamaan garis linier yang merupakan hubungan antara absorbansi (y) dengan konsentrasi (x) larutan standar sebagai berikut: $\mathrm{y}=-0,016604+0,00572128 \mathrm{x}$ dengan harga $r$ sebesar 0.9977. Hal ini menyatakan bahwa kurva kalibrasi memiliki keakuratan dalam penentuan konsentrasi sebesar $99 \%$. 
Penentuan kadar pengawet natrium benzoat dalam sampel dilakukan pengukuran absorbansi larutan sampel sebagai asam benzoat yang merupakan hasil ekstraksi. Konsentrasi ( $\mathrm{x}$ ) asam benzoat dalam sampel diperoleh dengan cara mensubstitusikan nilai absorbansi larutan sampel terhadap (y) pada persamaan $\mathrm{y}=-0,016604+$ 0,00572128x. Kemudian dilakukan perhitungan kadar pengawet natrium benzoat sebagai asam benzoat per $\mathrm{kg}$ sampel (1000 g), perhitungan ini didasarkan pada persyaratan yang dicantumkan dalam Peraturan Kepala BPOM RI No. 36 tahun 2013 yang menyatakan bahwa kadar pengawet benzoat dan garamnya dihitung sebagai asam benzoat.

Hasil analisis menunjukkan bahwa kadar asam benzoat rata-rata pada masingmasing sampel kecap manis yang dianalisis adalah: sampel A sebesar 407,1124 mg/kg; sampel B sebesar 499,9675 $\mathrm{mg} / \mathrm{kg}$; sampel C sebesar $347,7474 \mathrm{mg} / \mathrm{kg}$; dan sampel D sebesar 328,7509 $\mathrm{mg} / \mathrm{kg}$ (Data selengkapnya dapat dilihat pada Tabel 2).

Berdasarkan hasil penelitian ini menunjukkan bahwa ke 4 sampel kecap manis kemasan ulang yang dianalisis, kandungan pengawet natrium benzoatnya tidak melebihi ambang batas yang telah ditetapkan dalam Peraturan Kepala BPOM RI No. 36 tahun 2013 dan SNI 01-25431999 tentang persyaratan mutu kecap manis yaitu $600 \mathrm{mg} / \mathrm{kg}$ yang dihitung sebagai asam benzoat, dengan demikian ke 4 sampel tersebut aman untuk dikonsumsi.

\section{PENUTUP}

\section{Kesimpulan}

Berdasarkan hasil penelitian ini, maka dapat disimpulkan bahwa :

1. Kadar pengawet natrium benzoat yang dihitung sebagai asam benzoat dalam masing-masing sampel kecap manis yang dianalisis adalah: sebesar 407,1124 mg/kg; sampel B sebesar 499,9675 mg/kg; sampel C sebesar $347,7474 \mathrm{mg} / \mathrm{kg}$; dan sampel D sebesar $328,7509 \mathrm{mg} / \mathrm{kg}$

2. Kandungan pengawet natrium benzoat dalam ke 4 sampel kecap manis yang dianalisis memenuhi persyaratan yang ditetapkan dalam SNI 01-2543-1999 dan Peraturan Kepala BPOM RI No. 36 tahun 2013 yaitu tidak lebih dari 600 $\mathrm{mg} / \mathrm{kg}$.

\section{Saran}

Untuk melengkapi data penelitian tentang keamanan kecap manis khususnya kecap manis kemasan ulang, produk home industri maka perlu dilakukan penelitian lanjutan tentang persyaratan mutu lainnya seperti cemaran logam berat dan mikroba.

\section{DAFTAR PUSTAKA}

Anggrahini, Sri. 2012. Keamanan Pangan Kaitannya dengan Penggunaan Bahan Tambahan dan Kontaminan. Diakses $d i$ :http://lib.ugm.ac.id/digitasi/upload 1732_pp0906016.pdf pada tanggal 24 Desember 2017

BPOM, RI., 2013, Peraturan Kepala BPOM RI No. 36 tahun 2013, tentang Batas Maksimum Penggunaan Bahan Tambahan Pangan Pengawet, Jakarta

Kaunang, J. 2012. Identifikasi dan penetapan Kadar Pengawet Benzoat pada Saos Tomat Produksi Lokal yang Beredar diPasaran Kota Manado. Program Studi Farmasi Universitas Sam ratulangi, Manado.

Lutfi, A. 2009. Asam Benzoat. http://www.chem-is-

try.org/materi_kimia/kimialingkungan/zat-aditif/asam-benzoat/ , Diakses 23 Desember 2017

Menkes, 2012, Permenkes Nomor 033 Tahun 2012, Tentang Bahan Tambahan Pangan, Jakarta

Mulia, M., Syahrani, A., 1990. Aplikasi Analisis Spektrofotometer UV-VIS. Mecphiso Grafika. Surabaya

Tumalun, J. D. 2015. Analisis Konsentrasi Asam Benzoat sebagai Bahan Pengawet pada Saos Tomat secara Spektrofotometri UV-Vis. FMIPA Universitas Sam Ratulangi, Manado. 
